\title{
- COMUNICAÇÃO CIENTÍFICA - \\ INFLUÊNCIA DO ACÚMULO DE POEIRA SOBRE A EFICIÊNCIA DE PAINEIS FOTOVOLTAICOS NA REGIÃO OESTE PARANAENSE
}

Roger N. Michels, Universidade Tecnológica Federal do Paraná - Campus Medianeira, michels@utfpr.edu.br, José Airton A. dos Santos, Universidade Tecnológica Federal do Paraná - Campus Medianeira, airton@utfpr.edu.br,

Estor Gnoatto, Universidade Tecnológica Federal do Paraná - Campus Medianeira, gnoatto@utfpr.edu.br,

Marcos Fischborn, Universidade Tecnológica Federal do Paraná - Campus Medianeira, fisch@utfpr.edu.br,

Edward Kavanagh, Universidade Tecnológica Federal do Paraná - Campus Medianeira, kavanagh@utfpr.edu.br

\section{RESUMO}

A eficiência de painéis fotovoltaicos está relacionada a fatores construtivos da célula, bem como a fatores externos. Um dos fatores externos, que afeta negativamente a eficiência dos painéis fotovoltaicos, é o acúmulo de poeira sobre sua superfície superior. Este trabalho teve como objetivo quantificar a diferença, na eficiência, entre dois conjuntos de painéis fotovoltaicos Solarex, modelo MSX56, um limpo e outro sujo, na cidade de Medianeira/PR

Palavras-chave: eficiência, sujeira, painéis fotovoltaicos.

\section{INFLUENCE OF ACCUMULATION OF DUST ON THE EFFICIENCY OF PHOTOVOLTAICS PANELS IN THE WEST REGION OF PARANA STATE}

\section{ABSTRACT}

The efficiency of photovoltaic panels is related to factors of construction of the cell, as well as external factors. One of the external factors, which negatively affects the efficiency of photovoltaic panels, is the accumulation of dust on its upper surface. This work had as objective to quantify the difference in efficiency, between two sets of photovoltaic panels Solarex, MSX56 model, one clean and one dirty, in the city of Medianeira/PR.

Key-words: efficiency, dust, photovoltaic panels.

\section{INTRODUÇÃO}

A energia solar fotovoltaica está difundida em várias localidades do Brasil, aplicada a diversas finalidades. Por se tratar de uma fonte versátil, a energia solar fotovoltaica pode ser utilizada em locais remotos onde a rede elétrica ou não está disponível ou torna-se muito cara, sendo, desta forma, uma boa opção para pequenos agricultores (Treble, 1991).

Mas para a utilização desta forma de energia é necessário realizar um dimensionamento correto dos painéis fotovoltaicos, conhecer os equipamentos que serão alimentados e o potencial solarimétrico da região. No caso do Brasil, esta preocupação só deve ser levada em consideração na região sul, uma vez que o restante do território, estando mais próximo da linha do Equador, possui energia solar em abundância.

Muitas propriedades e comunidades rurais no Brasil, devido à grande distância das centrais de geração, não são atendidas com energia elétrica convencional. Uma das formas de garantir o suprimento de energia nessas propriedades ou comunidades rurais isoladas, seria a implantação de sistemas energéticos baseados em fontes alternativas de energia. Dentre elas, a energia solar é uma das mais promissoras, podendo ser utilizada no aquecimento de água por meio de coletores termossolares 
e geração de eletricidade, por meio de painéis fotovoltaicos, para iluminação e bombeamento de água (Cepel/Cresesb, 1999).

Para estudos mais precisos de desempenho de um painel fotovoltaico num determinado local, com vistas a um projeto específico, é recomendável a realização de medições locais, buscando avaliar as influências localizadas de irradiação, temperatura, relevo, poluição entre outros (Nawata \& Sadatomi, 1997).

Um fator que influência negativamente a eficiência de um painel fotovoltaico é o acúmulo de sujeira em sua superfície superior, com o passar do tempo (Becker, 1997). Uma gama grande de referências, sobre o assunto, divulgam a importância de se instalar os painéis fotovoltaicos com inclinação igual à latitude local, para uma melhor captura da irradiação e para que haja o escoamento da sujeira pela ação da chuva, porém isso, nem sempre, acontece, provocando o acúmulo de poeira na superfície de vidro dos painéis fotovoltaicos. Este trabalho teve como objetivo quantificar a diferença, na eficiência, entre dois conjuntos de painéis fotovoltaicos da marca Solarex, modelo MSX 56, um limpo e outro sujo, na cidade de Medianeira/PR.

\section{MATERIAL E MÉTODOS}

O sistema fotovoltaico (Figura 1), com dez painéis, foi montado na cidade de Medianeira, mais especificamente, nas dependências da Universidade Tecnológica Federal do Paraná. O município está localizado na Região Oeste Paranaense com $25^{\circ} 17^{\prime} 43^{\prime \prime}$ latitude Sul, $54^{\circ} 05^{\prime}$ $38^{\prime \prime}$ longitude Oeste e apresenta uma altitude de 500,7 metros. Dez painéis fotovoltaicos foram instalados (Figura 1), mas somente quatro foram utilizados neste trabalho (dois painéis sujos e dois painéis limpos). Devido à configuração do sistema os painéis foram ligados dois a dois em série.

O sistema fotovoltaico foi formado por:

- Quatro painéis solares, fabricante Solarex, modelo MSX 56, tensão padrão de $12 \mathrm{~V}$, corrente padrão de $3,35 \mathrm{~A}$ e potência de $56 \mathrm{~W}$;

- Um micrologger da marca Campbel
Scientific-INC, modelo CD23X;

- Um termopar do tipo K (cromo/alumínio) aferido para a aquisição de dados;

- Um piranômetro Kipp \& Zonen CM3;

- Dois divisores de tensão;

- Duas resistências Shunt;

- Baterias recarregáveis estacionárias de chumbo-cálcio, marca Concorde, modelo PVX1285 (85Ah-12 V);

- Controlador de carga e descarga do sistema de armazenamento, marca Morningstar Prostar 30 (30 A).

O termopar, colocado na parte de trás do painel fotovoltaico, fornece $\mathrm{o}$ valor da temperatura dos painéis e o piranômetro (Figura 2) o valor da irradiação. Os divisores de tensão e as resistências Shunt forneceram os valores de tensão e corrente das duas configurações de painéis.

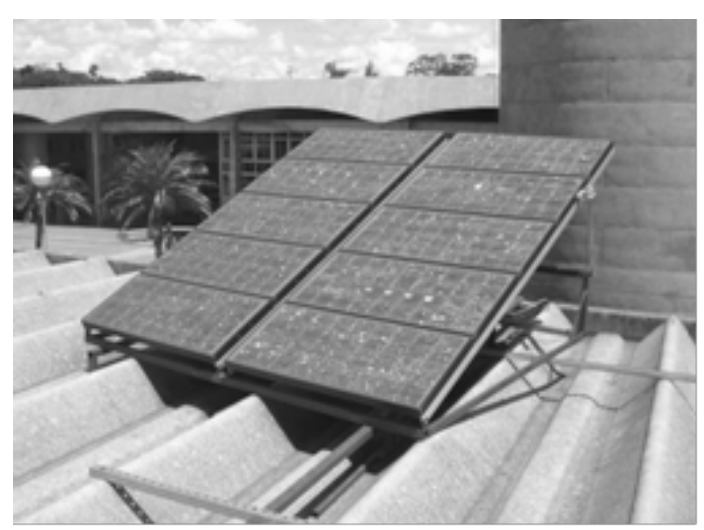

FIGURA 1. Sistema fotovoltaico.

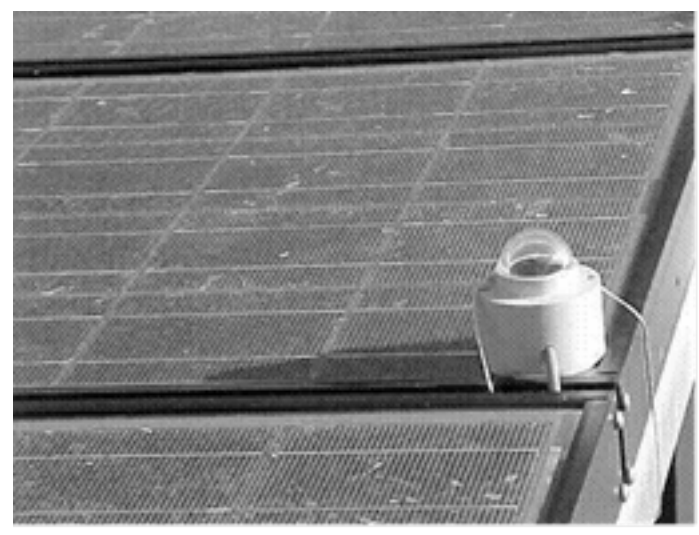

FIGURA 2. Piranômetro Kipp \& Zonen. 
O posicionamento do conjunto fotovoltaico foi realizado por meio de uma haste vertical projetada sobre um plano horizontal, pela localização do norte geográfico utilizando o valor do meio-dia real (12 horas, 43 minutos, 44 segundos). O ângulo de inclinação do conjunto fotovoltaico em relação ao plano horizontal foi mantido constante e idêntico à latitude do local.

O sistema, em estudo (Figura 3), é formado por: um conjunto fotovoltaico, um controlador de carga, um banco de baterias e por uma carga resistiva. $\mathrm{O}$ sistema de aquisição de dados é constituído por um datalloger da CAMPBELL SCIENTIFIC-INC modelo CR23X, programado para realizar uma leitura por segundo de cada canal e armazenar a média aritmética de um minuto dos seguintes dados: componente da radiação global de incidência no painel; temperatura de operação do painel; tensão e corrente do sistema fotovoltaico.

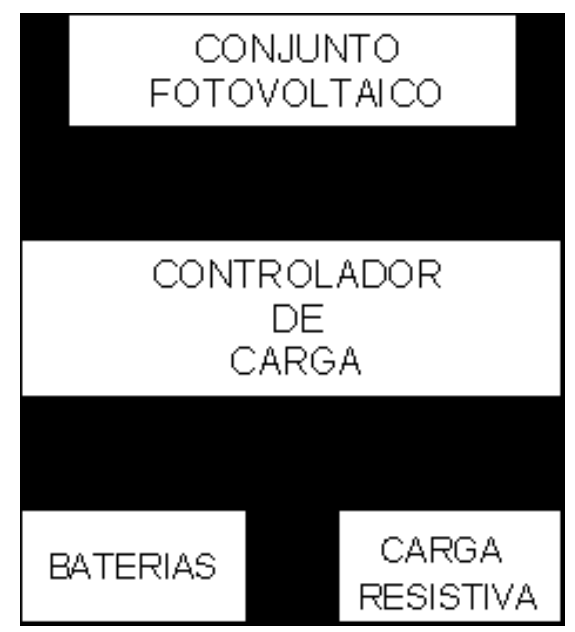

FIGURA 3. Sistema em estudo.

Os painéis fotovoltaicos foram configurados para que dois deles trabalhassem limpos e dois trabalhassem sujos. Os painéis sujos estão a um período de dois anos trabalhando sem limpeza. Portanto, a sujeira acumulada depositou-se de forma natural.

\section{RESULTADOS E DISCUSSÃO}

Na Figura 4 apresentam-se as curvas das correntes para as duas configurações de painéis fotovoltaicos, um dia antes da limpeza. Sendo a configuração, Sujo B, a configuração de painéis que depois foi limpa. A seguir, na Figura 5 apresentam-se as curvas para as configurações de painéis Sujo e Limpo.

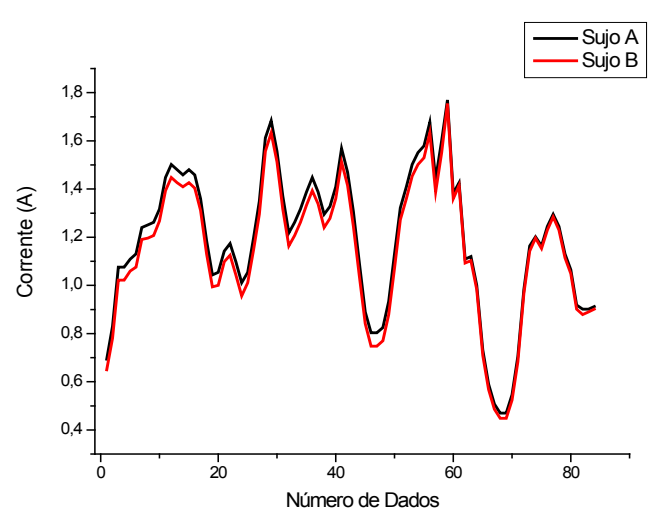

FIGURA 4. Curvas dos painéis antes da limpeza.

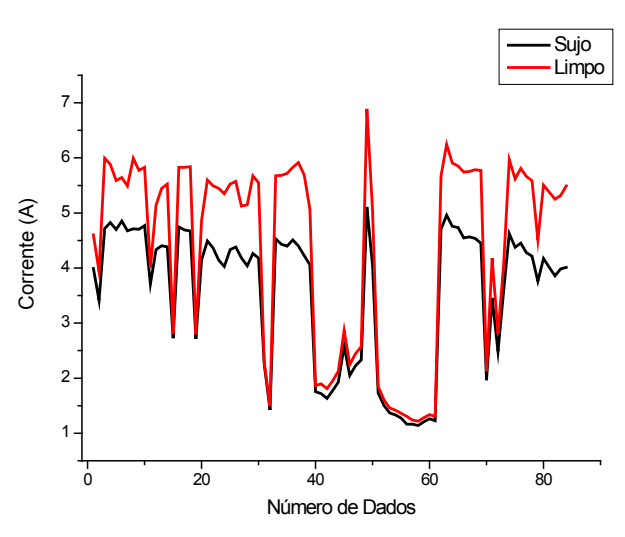

FIGURA 5. Curvas dos painéis após a limpeza.

Verificou-se, após análise e comparação dos dados, que a configuração painéis limpos apresentou uma eficiência 16,26\% maior que a configuração de painéis sujos.

\section{CONCLUSÕES}

Neste trabalho apresentaram-se resultados de campo de um gerador fotovoltaico de silício policristalino, da marca Solarex, 
modelo MSX 56. Concluiu-se, que é de suma importância fazer limpezas periódicas nos painéis fotovoltaicos, para não ocorrer perda de eficiência.

\section{REFERÊNCIAS BIBLIOGRÁFICAS}

BECKER, H. Reduced output of generation due to pollution. Barcelona: EUPU, 1997.

CEPEL/CRESESB Manual de engenharia para sistemas fotovoltaicos. Rio de Janeiro: CEPEL/CRESESB, 1999.

NAWATA, Y.; SADATOMI, M. Prediction of photovoltaic (PV) power output considering weather effects. Colorado: Solar, 2006.

TREBLE, F.C. Generanting electricity from the sun. New York: Pergamon Press, 1991. 